\title{
Mathematical models of agricultural production management in high risk environments
}

\author{
Yaroslav Ivanyo, Nina Fedurina*, and Zhanna Varanitsa-Gorodovskaya \\ Irkutsk State Agricultural University named after A.A. Ezhevsky Molodezhny, Irkutsk, Russia
}

\begin{abstract}
The paper presents an algorithm for modeling the production of agricultural products in the formation of agrometeorological events. Stochastic models of variability of downpours, early snow-fall and crop yields are constructed to assess the likelihood of extreme events. Based on a probabilistic assessment of crop bio-productivity by a normative method, economic losses from agrometeorological events are determined. A model for optimizing crop production taking into account natural risks was built and implemented for an agricultural organization. The results were obtained according to data of the Irkutsk district.
\end{abstract}

\section{Introduction}

In the Irkutsk region, livestock and crop production are traditionally developed. On its territory with different climatic conditions, products are produced, the volume of which is $5-7 \%$ of the gross regional product. Moreover, the yield of grain crops in recent years is the largest among the subjects of the Siberian Federal District [1, 2].

Meanwhile, extreme agrometeorological and hydrological events strongly influence agriculture. Among them are droughts, rain floods and spring floods, downpours and early snowfalls. Situations of the manifestation of two events of different origin in one year are possible [3]. Each agrometeorological and hydrological event has a specificity of variability. It especially affects agricultural production, which implies management of enterprises at risks corresponding to high probability.

The paper considers situations of agricultural production by an enterprise under the strong influence of agrometeorological events and their description using a linear mathematical programming model with random parameters. It is proposed to optimize the production of agricultural products in adverse climatic conditions. Such cases are possible in the activities of the agricultural producer using at least partially the resource potential. Obviously, during a catastrophic agrometeorological or hydrological event like the June rain flood of 2019, the work of an agricultural enterprise is impossible.

Therefore, the paper considers models taking into account partial economic losses by the producer.

The aim of the work is to create a model for optimizing the production of agricultural products, taking into account the variability of various agrometeorological events during the growing season and harvesting to mitigate damage.

${ }^{*}$ Corresponding author: fedurina_n@mail.ru 
In accordance with the goal, the following tasks are defined:

- to build stochastic models of variability of agrometeorological events that strongly affect the production of agricultural products, taking into account their features;

- identify risks caused by agrometeorological events;

- to build an optimization model for the production of agricultural products in conditions of risks and apply it at a real facility.

\section{Materials and methods}

In this work, we used the data of the Irkutsk Department for Hydrometeorology and Environmental Monitoring for daily temperatures and precipitation during the growing season, as well as atmospheric phenomena in Irkutsk for 1968 - 2016. The information of annual reports on the state of the environment of the Irkutsk region for $2000-2018$ is analyzed. The series of crop yields according to the data of the Irkutsk region for 1996 2019 are considered. To implement the proposed optimization models, the financial statements of the agricultural organization CJSC "Irkutskiye semena", located in the Irkutsk district, were used.

Since the task of optimizing the production of agricultural products in the face of uncertainty makes it possible to obtain many optimal solutions using different methods, the work of various authors involved in the development and implementation of such tasks is considered. The authors of [4-10] propose optimization models for solving problems related to business processes, planning, and management under conditions of uncertainty and risk. At the same time, various research objects are described: different business processes [4], production and sales of products by an enterprise [5], a multi-level process for managing an enterprise's production activities in a risk environment [6], planning food production [7 - 9] and the use of land resources [10].

It is clear that it is possible to optimize the production of agricultural products under the influence of adverse external factors if we analyze in detail the natural and climatic features of the agricultural territories. In a number of works [11 - 15], factors of regions with different weather conditions are assessed to determine the risks in obtaining agricultural products.

Each territory has its own characteristics associated with the origin of extreme agrometeorological and hydrological extreme events, their frequency and combination. In [16], attention was drawn to the need for the correct spatial distribution of agricultural production, depending on economic and climatic factors. Some authors highlight the importance of agricultural specialization [17] and the cyclical development of the agricultural sector in Russia [18]. Thus, the modeling of agricultural production defines various aspects of increasing the level of managerial activity, which are interrelated.

In [3], optimization models with uncertain parameters were proposed that take into account the properties of exclusively climatic events. However, other situations are possible when events do not stand out in the sequence of the studied parameter and the series is considered as a homogeneous sample.

Then it is necessary to evaluate the anomalous values belonging to the tail parts of the probability distribution. The paper considers the optimization of agricultural production, taking into account random estimates of the tail parts of the distribution laws. At the same time, the features of agroclimatic events of different origin were studied for an adequate mathematical description of the production of agricultural products under risk conditions. The solution of such problems touches on the issues of proper planning of agriculture in the conditions of the specific territory and natural and climatic factors. 


\section{Results and discussion}

To build and implement models for optimizing agricultural production, the following algorithm is proposed. Firstly, according to hydrometeorological observations, extreme events are assessed that most affect the agricultural production of a particular territory. Secondly, a case is identified that corresponds to the low probability of the manifestation of an agrometeorological and hydrolytic event. Thirdly, the relationships between natural factors and the damage caused by extreme events are determined. Fourth, the variability of the parameters included in the mathematical model is estimated. When revealing the randomness of a parameter, the laws of probability distribution are selected to describe it. Fifth, for the case with a low probability, a model for optimizing agricultural production is being built. Sixth, the optimal solution is determined taking into account the scattering of probability.

The works $[3,18,19]$ show the influence of different climatic events on agriculture in the Irkutsk region. Extreme events causing significant damage to agricultural producers include: droughts, rain floods, spring floods, congestion, downpours, thunderstorms, hurricanes, early snowfalls, frosts. The greatest risks in the production of agricultural products are associated with droughts. A particularly severe drought in the region was observed in 2015 [18], the recurrence of which was 1 time in 17 years. Catastrophic events like the rain flood that took place in 2019 on the Iya river manifest themselves much less frequently. Meanwhile, this hydrological phenomenon paralyzed the work of many farms in the Tulun district.

In addition to drought, we highlight rainfall that damages crops, forms water erosion, and contributes to soil degradation. Heavy rainfall occurred in 2001. They caused damage to agriculture in the Irkutsk and Angarsk districts and became one of the main factors of rare floods on the Kitoy and Irkut rivers. We note one more unfavorable climatic event, called early snowfall. In some years, in particular in 2002, from this phenomenon during the harvesting period from September 16 to September 18, in the fields of the main agricultural districts of the Irkutsk region, a significant part of the lodged bread died as a result of waterlogging, germination of grain and fungal diseases [19].

These three agrometeorological events affecting the activities of agricultural producers will be considered.

The probability of occurrence of droughts can be determined by the value of the yield of grain crops. The long-term series of productivity of wheat, oats and barley, which are the most common in the Irkutsk region, are considered. Statistical processing of cereal sequences for the period 1996 - 2019 showed that they are random. However, no significant autocorrelation coefficients were found in the series. In addition, the negative asymmetry of the samples is noteworthy. The laws of probability distribution, with which you can describe the variability of crops, are shown in table 1 . The results were obtained from the bio-productivity of three crops cultivated in the Irkutsk districts.

Analysis of continuous rainfall over the duration of rainfall shows that, as a rule, they differ little from the largest daily rainfall. Therefore, as an estimate of showers, the layers of the largest daily precipitation were used. Table 1 shows the probability distribution of Pearson type III, which corresponds to empirical data. To assess the correspondence of the analytical functions to the actual data on the yield of grain crops and the largest daily precipitation, the properties of the given probability distribution laws and the Kolmogorov consent criterion were used. 
Table 1. Laws of probability distribution for the description of grain crops, highest daily rainfall, soll erosion early and snowfall by data of the Irkutsk district

\begin{tabular}{|c|c|c|c|c|}
\hline Characteristic & Probability distribution law & $x$ & $\mathrm{Cv}$ & Cs \\
\hline $\begin{array}{l}\text { Wheat yield, } \\
\text { c/ ha }\end{array}$ & $\begin{array}{l}p(x)=\frac{1}{\sigma \sqrt{2 \pi}} \exp \left[-\frac{(x-\bar{x})^{2}}{2 \sigma^{2}}\right] \\
\text { where } \bar{x} \text { is the average, } \sigma \text { is standard deviation. }\end{array}$ & 16,6 & 0,195 & 0 \\
\hline $\begin{array}{l}\text { Barley } \\
\text { productivity, } \\
\text { c/ ha }\end{array}$ & $\begin{array}{l}\text { Three-parameter power gamma distribution } \\
p(x)=\left[\frac{\Gamma(\gamma+b)}{\Gamma(\gamma)}\right]^{\gamma / b} \frac{1}{\Gamma(\gamma)|b| \bar{x}}\left(\frac{x}{\bar{x}}\right)^{\gamma / b-1} \times \\
\times \exp \left\{-\left[\frac{x}{\bar{x}} \frac{\Gamma(\gamma+b)}{\Gamma(\gamma)}\right]^{1 / b}\right\}, \\
\text { where } \bar{x} \text { is the average, } \gamma \text { and } b \text { are parameters } \\
\text { related by the coefficients of variation of } C_{v} \text { and } \\
\text { asymmetry of } C_{s .}, \Gamma(\gamma) \text { is gamma function. }\end{array}$ & 16,0 & 0,237 & $-0,24$ \\
\hline $\begin{array}{c}\text { Productivity } \\
\text { oats, c/ ha }\end{array}$ & & 15,8 & 0,203 & $-1,05$ \\
\hline $\begin{array}{l}\text { The highest } \\
\text { daily rainfall } \\
\text { in July, } \mathrm{mm}\end{array}$ & $p(x)=\frac{\gamma^{\prime}}{\Gamma(\gamma)(\bar{x}-l)}\left(\frac{x-l}{\bar{x}-l}\right) e^{-\gamma(\overline{\bar{x}-l})}$ & 31,5 & 0,53 & 1,40 \\
\hline $\begin{array}{l}\text { The highest } \\
\text { daily rainfall } \\
\text { in June, } \mathrm{mm}\end{array}$ & $\begin{array}{l}\text { where } \bar{x} \text { is the average, } \gamma \text { and } l \text { are parameters } \\
\text { related by the coefficients of variation of } C_{v} \text { and } \\
\text { asymmetry of } C_{s . .}\end{array}$ & 25,5 & 0,83 & 2,79 \\
\hline $\begin{array}{l}\text { Soil erosion, } \mathrm{t} \\
\text { / ha }\end{array}$ & $\begin{array}{c}\text { Truncated gamma distribution } \\
p(x)=\frac{2 \gamma^{\gamma}}{\Gamma(\gamma) \bar{x}}\left(\frac{x}{\bar{x}}\right)^{\gamma-1} e^{-\gamma\left(\frac{x}{\bar{x}}\right)} \text { at } x>x_{\text {med }}\end{array}$ & 18,1 & 1,63 & 3,26 \\
\hline $\begin{array}{l}\text { The amount of } \\
\text { precipitation } \\
\text { falling in late } \\
\text { August and } \\
\text { the first two } \\
\text { decades of } \\
\text { September } \\
\text { (early } \\
\text { snowfall), mm }\end{array}$ & $\begin{array}{l}\text { Gamma distribution taking into account zero values } \\
\qquad \begin{array}{l}\text { of a series } \\
\qquad=n_{1} p_{1} /\left(n_{1}+n_{2}\right)\end{array} \\
\text { where } n_{1}, n_{2} \text { are the number of non-zero and zero } \\
\text { values of the series; } p_{1} \text { are probabilities } \\
\text { corresponding to the law of probability distribution } \\
\text { without zero values. }\end{array}$ & 11,5 & 1,66 & 3,32 \\
\hline
\end{tabular}

Based on the above results, the series of the highest daily precipitation have a greater dispersion value compared to the bioproductivity of crops. Moreover, they are characterized by positive and high asymmetry.

In addition to describing the variability of the highest daily precipitation, a truncated gamma distribution is given to estimate the probabilities of water erosion of the soil according to the Irkutsk district. In the formation of a series characterizing the annual 
potential soil erosion, the calculation method described in [20] was used. The formula for the potential hazard of soil erosion under the influence of liquid precipitation has the form

$$
A=R K L C P,
$$

where $R$ is rain erosion factor, $K$ is erosion tolerance factor, $L, S$ are slope length and steepness factors, $C$ is vegetation and crop rotation factor, $P$ is erosion control efficiency factor. When calculating the potential hazard, the values of $C$ and $P$ are taken equal to unity.

It should be noted that the accuracy of constructing the laws of probability distribution depends on the methods for calculating the statistical parameters of the studied samples [21]. The statistical parameters characterizing the average value, the coefficients of variation and asymmetry $\left(\bar{x}, C_{v}\right.$ и $\left.C_{s}\right)$, were obtained by the method of moments. An exception is the calculation of soil erosion. Here, the parameters of the truncated gamma distribution were calculated by the approximate maximum likelihood method [22].

And, finally, a description of the early snowfall was carried out on the basis of a formed series of solid precipitation during the harvesting period (late August - first two decades of September). A feature of such a sample is the presence of zero values, which are determined in years when early solid precipitation was not observed. Table 1 shows the calculation formula for estimating the values of the gamma distribution function taking into account zero and non-zero data, recommended in the book [23].

The given laws of probability distribution make it possible to determine the probabilities of the formation of agrometeorological events. Table 2 shows the probabilities of the manifestation of three agrometeorological events that significantly affected the production of agricultural products. The July downpour of 2001, which caused damage to agricultural producers in the Irkutsk district, is estimated by the probability of the highest daily rainfall to be $p$ less than 0.01 . This value was obtained according to the distribution law of Pearson type III for a series of perennial rainfall for July. Early snowfall is more common. The probability of occurrence of an event similar to 2002 was more than 0.10 according to the gamma distribution with zero sample members. As for the drought of 2015 , the probability of this phenomenon, calculated on the basis of the laws of probability distribution given in Table 2 corresponds to a little over 0.030 . This value is determined taking into account the probabilities of low yields of wheat, oats and barley, as well as weight coefficients characterizing the sown area of these crops.

Table 2. General damage to grain crops on the area under crops 12781.5 hectares according to the data of the Irkutsk district

\begin{tabular}{|c|c|c|c|c|c|c|c|c|}
\hline $\begin{array}{c}\text { Years } \\
\text { of } \\
\text { events }\end{array}$ & $\begin{array}{c}\text { Event } \\
\text { type }\end{array}$ & $\begin{array}{c}\text { Average yield } \\
\text { over the past } \\
5 \text { years }\end{array}$ & $\begin{array}{c}\text { Productivity } \\
\text { per year of } \\
\text { the event }\end{array}$ & $\begin{array}{c}\text { Damage, } \\
\text { ton }\end{array}$ & $\begin{array}{c}\text { Damage, } \\
\text { thousand } \\
\text { rubles }\end{array}$ & $\begin{array}{c}\text { Damage, } \\
\%\end{array}$ & $\begin{array}{c}\text { The cost } \\
\text { of } \\
1 \mathrm{t} \text { of } \\
\text { grain, } \\
\text { thousand } \\
\text { rubles }\end{array}$ & $\begin{array}{c} \\
\\
p \\
p \\
\text { events }\end{array}$ \\
\hline 2001 & Downpour & 15,3 & 13,0 & 3693,16 & 16619,22 & 15,1 & 4,5 & $\begin{array}{c}0,0078 \\
3 \\
\end{array}$ \\
\hline 2002 & $\begin{array}{c}\text { Early } \\
\text { snowfall }\end{array}$ & 14,3 & 11,7 & 3172,74 & 14277,33 & 18,2 & 4,5 & 0,120 \\
\hline 2015 & Drought & 18,4 & 8,9 & 12060,45 & 96121,77 & 51,7 & 7,97 & 0,0305 \\
\hline
\end{tabular}

Formed agrometeorological events caused significant damage to producers of the Irkutsk region (table 2). Losses calculated by the methodology described in the document [24] range from 14.3 to 96.1 million rubles. Damage from the drought of 2015 associated 
with the production of crops amounted to more than $50 \%$ relative to the average crop over the previous 5 years.

Let us consider the possibility of optimizing the production of crop products in the formation of agrometeorological phenomena.

In [3], a model was proposed for optimizing the production of agricultural products taking into account a rare natural (climatic) event, which can be used to solve planning problems in the face of risks. We will use this mathematical programming task for a special case in which the production of only crop products is taken into account. Here is a model for optimizing crop production with an impact on the activities of producers of one event.

When constructing an optimization model, crop production volumes as the desired quantities were used. The optimality criterion is selected in the form of income from the industry with the achievement of the maximum value:

$$
f=\sum_{s \in S} \alpha_{s} x_{s} \rightarrow \max
$$

where $a_{s}$ is income per ton of manufactured products $s$.

The following restrictions are constructed.

Firstly, inequalities in the use of sown areas for all crops and for each individual are determined:

$$
\begin{gathered}
\sum_{s \in S} \frac{x_{s}}{y_{s}^{p}} \leq B, \\
\frac{x_{s}}{y_{s}^{p}} \leq b_{s}, \\
B=\sum_{s \in S} b_{s},
\end{gathered}
$$

where $B$ is sown area, $b_{\mathrm{s}}$ is crop area $s, y_{s}^{p}$ is crop yield $s$ with estimated probability $p$.

Secondly, labor costs for obtaining agricultural products were taken into account:

$$
\sum_{s \in S} \beta_{s} x_{s} \leq A
$$

where $\beta_{s}$ are labor costs for the production of one ton of products $s, A$ are farm labor.

Thirdly, there is a restriction on labor remuneration for production:

$$
\sum_{s \in S} z_{s} x_{s} \leq Z
$$

where $z_{s}$ is wages of one ton of manufactured products, $Z$ are the possibilities of the economy to pay.

Fourth, it is necessary to take into account the volume of sales of products and supplies for each of its types:

$$
\sum_{s \in S} x_{s} \geq D^{p}
$$




$$
x_{s} \geq d_{s}^{p},
$$

where $D^{\mathrm{p}}$ is sales volume of all products that are subject to random fluctuations due to climatic events, $d_{s}^{p}$ are sales volumes $s, p$ is probability. Model (2) - (9) was implemented for one of the agricultural organizations of the Irkutsk district (CJSC "Irkutsk semena"), which specializes in the production of potatoes and grain crops.

Based on the application of the constructed model, five variants of optimal plans corresponding to maximum incomes were obtained. Table 3 shows solutions to a linear programming problem with random estimates when production is affected by rainfall, early snowfall, and droughts. Unknown in the model are the volumes of wheat production $\left(x_{1}\right)$; barley $\left(x_{2}\right)$, oats $\left(x_{3}\right)$, potatoes $\left(x_{4}\right)$, perennial grass seeds $\left(x_{5}\right)$ and rapeseed $\left(x_{6}\right)$. In addition, optimal solutions were determined for favorable and averaged conditions when conducting agricultural production.

Table 3. Results of modelling production of agrarian production in various agrometeorological conditions

\begin{tabular}{|c|c|c|c|c|c|c|c|}
\hline Conditions & Wheat & Barley & Oats & Potatoes & $\begin{array}{c}\text { Perennial } \\
\text { herbs }\end{array}$ & Rape & $\begin{array}{c}\text { Goal } \\
\text { function }\end{array}$ \\
\hline $\begin{array}{c}\text { Ton } \\
\text { Tavorable } \\
\text { conditions }\end{array}$ & 5145 & 1205 & 406 & 11200 & 195 & 126 & 191614,380 \\
\hline $\begin{array}{c}\text { Average } \\
\text { conditions }\end{array}$ & 3486 & 778 & 316 & 8680 & 167 & 117 & 142836,381 \\
\hline Downpour & 2247 & 564 & 334 & 8120 & 152,9 & 126 & 129528,487 \\
\hline Early snowfall & 2478 & 544 & 242 & 8600 & 166,8 & 108 & 129808,630 \\
\hline Drought & 2331 & 326 & 200 & 5673 & 139 & 104 & 126672,940 \\
\hline
\end{tabular}

In accordance with the results, the economic losses of the agrarian producer from the effects of rainfall, early snowfall and drought relative to conditions with averaged indicators for the values of the objective function amounted to $9.32,9.12$ and $11.3 \%$. It should be added that partial crop losses in 2001 were caused by a decrease in soil fertility by $0.6 \mathrm{~cm}$ (1). In monetary terms, the damage amounted to more than 2.5 million rubles. At the same time, the volumes of possible sales of products range from 8748 (drought) to 13543 tons (average conditions for production). The agricultural producer suffered the most from the drought of 2015. The results obtained correspond to the following probabilities calculated according to the laws of grain yield of distribution. In a year of heavy rainfall, the probability of low bioproductivity of wheat and barley was 0.0337 and 0.139 . The oats harvest was not harmed. In conditions of early snowfall, the probabilities of wheat, barley and oat yields correspond to the values of $0.0681,0.118$ and 0.134 , and for severe drought they were $0.0440,0.0104$ and 0.0340 .

The potential of the agricultural organization is noteworthy. Under favorable conditions, it is possible to increase production by $34.2 \%$ relative to average production indicators. Thus, with proper management of land, labor and prices, risks can be mitigated.

Since the above results characterize situations that have taken place in different years of development of the economy, for a comparative analysis, data on some resources for 20152019 were used. It should be borne in mind that on the farm of CJSC "Irkutsk semena", the cultivation of rapeseed is at the initial stage. At the same time, crops are carried out in small areas. Nevertheless, the results obtained adequately reflect the activities of the agricultural organization.

The above algorithm for modeling agricultural production is applicable for each agricultural industry and their combination. The calculations were performed for one of the 
farms in the Irkutsk district and in accordance with the dynamics of the agricultural indicators of this territory. Such work, taking into account the climatic features, can be implemented for other areas of the Irkutsk region and adjacent territories.

\section{Conclusion}

The features of the dynamics of agrometeorological events affecting the production of agricultural products in the south of the Irkutsk region are analyzed.

Stochastic models of the variability of the highest daily precipitation, solid precipitation during harvesting and yield of grain crops are constructed.

The economic damage caused by heavy rainfall, early snowfall and drought was identified, and the likelihood of agrometeorological events was assessed.

A model for optimizing crop production with random parameters is built. It was implemented for an agricultural organization. A comparison of the results of optimizing the activities of the agricultural producer was made for a favorable situation, averaged production indicators, as well as in conditions of heavy rainfall, early snowfall and drought.

The resulting decisions contribute to better risk management.

\section{Acknowledgment}

The some results study was obtained with funded by RFBR according to the research project no. 19-07-00322

\section{References}

1. Ya. M. Ivanyo, N.N. Dmitriev, Monograph, 1, 319 (2019)

2. Ya. M. Ivanyo, N.N. Dmitriev, Monograph, 2, 321 (2019)

3. Ya. M. Ivanyo, Monografiya, 180 (2015)

4. A. G. Madera, Business Informatics, 4 (42), 74 (2017)

5. Y. Kurudzhi, Eastern European Journal of Enterprise Technologies, 4(3), 12 (2015)

6. V. Babenko, M. Salem Abdel-Badeh, International journal of Economics and statistics, 6, 99 (2018)

7. Ya. M. Ivanyo, Scientific and practical journal Vestnik IrGSHA, 75, 119 (2016)

8. Ya. M. Ivanyo, Advances in Intelligent Systems Research, 158, 78 (2018)

9. I.V. Sokolova, Scientific Journal of KubSAU, 120, 1 (2016)

10. N. Svetlov, IAMO Forum 2017: Eurasian Food Economy between Globalization and Geopolitics, 1 (2017)

11. L.V. Kireicheva, International Research Journal, 12 (66), 3, 110 (2017)

12. V. V. Chapurko, M. D. Chapurko, Economic sciences, 103, 19 (2007)

13. T.B. Shivrina, Yu.V. Davydova, Basic research, 12-10, 2208 (2014)

14. I. S. Shelobayeva, Bulletin of Tula State University. Economic and legal sciences, 4-1, 66 (2014)

15. Agricultural Economics of Russia, 3, 60 (2016)

16. T.M. Kasimova, Basic research, 2-1, 3797 (2015)

17. A. M. Nosonov, National interests: priorities and security, 1 (238), 24 (2014) 
18. Ya. M. Ivanyo, Current trends and prospects for the development of hydrometeorology in Russia: materials of II All-Russia. scientific-practical Conf., dedicated to the 55th anniversary of the Department of Hydrology and Environmental Management, 35 (2019)

19. "State Report on the State and Environmental Protection of the Irkutsk Region in 2002", 327 (2004)

20. SS 17.4.4.03-86 Nature Protection (ESS). Soils. Method for determining the potential risk of rain erosion

21. P. Van Gelder, Proceeding Intenftional scientific seminar, 11 (2004)

22. Construction Norms and Regulations 2.01.14-83. Determination of design hydrological characteristics, Gosstroy of the USSR, M .: Stroyizdat, 35 (1985)

23. Toolkit for determining hydrological characteristics, 418 (1984)

24. Order of the Ministry of Agriculture of the Russian Federation no. 87 of 1 March 2019 "On Approval of the Methodology for Determining the Insurance Cost and Amount of Loss (Death) of Crop Crops and Planting of Perennial Plantations and the Methodology for Determining the Insurance Cost and Amount of Loss (Death) of Farm Animals" (2019) 